\title{
WHITE GOLDS: \\ A QUESTION OF COMPROMISES
}

\section{CONVENTIONAL MATERIAL PROPERTIES COMPARED TO ALTERNATIVE FORMULATIONS}

\author{
Greg Normandeau \& Rob Roeterink \\ Imperial Smelting \& Refining Co. of Canada Ltd. \\ Markham, Ontario, Canada
}

The initial review of white gold research, summarized at the 1992 Santa $\mathrm{Fe}$ Symposium on Jewellery Manufacturing Technology was extended into an investigation of the physical properties of numerous white gold formulations.

Attributes such as colour, hardness, melting temperature, tensile strength, cold working performance, investment cast form filling, fire-cracking tendency and

nickel allergy response were quantified. Properties of experimental alloys developed from the work of previous studies or new combinations of elements were compared to nickel bleached carat gold materials. Secondary base metal bleaches such as iron and cobalt did not improve the performance of nickel white golds. Formulations based on the bleaching action of palladium combined with copper exhibited comparable or improved physical properties and commercial viability. Free from nickel, with significantly reduced melting temperatures compared to palladium-silver formulations, these materials were directly compared with conventional carat alloys. Positive opinions from field testing reinforced laboratory results. Nickel remains the least expensive commercially viable bleach of gold. The cost of palladium additions is a detrimental factor restricting widespread application for high volume, low cost jewellery. Where the unique properties of palladium white golds are beneficial for hand crafted items, their additional cost can be justified. 


\section{INTRODUCTION}

This article represents the second half of an extensive undertaking to review the attributes of a broad range of commercial white golds and evaluate alternative formulations. General dissatisfaction with the physical properties and performance of white golds compared with their yellow counterparts, combined with a concern for the allergenic effects of nickel, served as impetus for the study. The first half of the topic was presented at the 1992 Santa Fe Symposium on Jewellery Manufacturing Technology. An article entitled 'White Golds: A Review of Commercial Material Characteristics \& Alloy Design Alternatives' was published in autumn 1992 [1].

That article reviewed the origins, positive features and negative attributes of nickel white golds and palladium-based compositions. Previous investigations by numerous authors into alternative formulations to improve shortcomings were summarized. The potential need for nickel-free compositions in response to European concerns was noted. Extension of previous work on 18 carat alloys to common North American 10 and 14 carat materials was an objective. The overall issue of compromise on various physical properties versus material intrinsic cost was a significant theme.

\section{REQUIREMENTS FOR COMMERCIAL WHITE GOLD MATERIALS}

The attributes desirable in white golds remain the focus of the investigation. The relative importance of each property varies with material application. Achievement or enhancement of one property over the other was the tradeoff inherent in alloy design. As summarized by O'Connor [2], requirements include the following:

\section{Primary Requirements}

1. Suitable white colour and high reflectivity.

2. A reasonable hardness in the cast or annealed state (arbitrarily, less than 200 Vickers hardness).
3. Adequate cold workability (arbitrarily, greater than $25 \%$ elongation under tensile loading).

4. A liquidus temperature suitable for conventional manufacturing techniques (arbitrarily, less than $1100^{\circ} \mathrm{C}$ ).

5. Alloying constituents must be the least expensive necessary to impart the desired properties.

\section{Secondary Requirements}

6. Materials must be amenable to soldering or brazing techniques for assembly.

7. Materials must be amenable to rhodium plating for colour enhancement.

8. Susceptibility to fire-cracking must be minimized.

9. Recycling of process scraps must be possible with no significant difficulties.

10. Materials must be resistant to tarnish or corrosion.

As noted in the previous article, achievement of these 10 attributes simultaneously is very difficult given the metallurgical limitations of the elements employed for fabricating commercial white golds. Compromises between the requirements are routinely made with conventional materials [3].

Subdivision of the investigation was as shown in Figure 1. The various branches are purely arbitrary divisions for the sake of discussion. Conventional

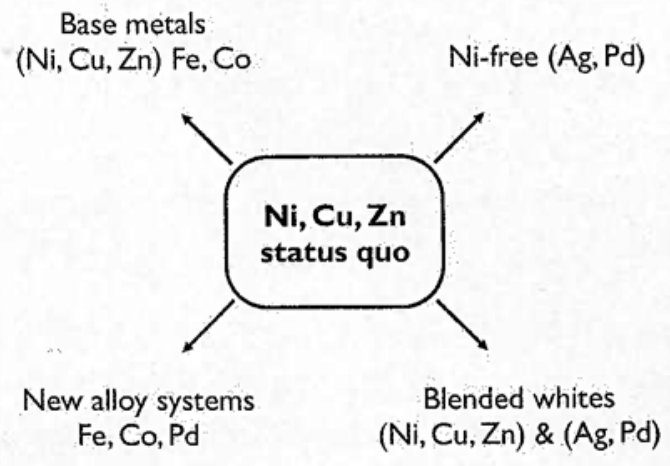

Figure 1

Subdivision of white gold topic into four categories for evaluation 
nickel-containing white golds were tested with objective methodology to establish a standard for comparison. Study of blended white golds was based on the work of Susz and Linker [4]. Base metal white golds imply additions of iron and cobalt to typical nickel white golds previously examined by O'Connor $[2,5]$. Nickel-free white golds are self-explanatory while the fifth category, new alloy systems, is a generic name for formulations that did not fit within the other divisions. For discussion of the attributes, strengths and weaknesses of each subdivision, a certain pattern of physical property evaluation was followed.

\section{EXPERIMENTAL TECHNIQUE}

\section{Colour Evaluation}

To be in line with current efforts to standardize objective colour measurement through the MJSA and Santa Fe Symposium Technical Committees, the CIELAB system of colour measurement was employed [6]. Colour coordinates were measured on $1 / 2$ inch square coupons with a 600 grit random scratch surface finish cleaned with an alcohol wipe. The illuminant was source $C$ with an observer set at 2 degrees. Both the specular and ultraviolet components were included. Figure 2 illustrates the colour basis of the CIELAB coordinates. The colour coordinates $a^{*}, b^{*}$ and $L^{*}$ were compared to a standard $95 \%$ platinum $-5 \%$ cobalt whiteness by means of a computed colour vector expressed as DE. This value represents the length of a colour vector in three dimensional space from the target point. The following relationship produced the vector magnitude:

$$
D E=\sqrt{\left(a_{2}^{*}-a_{1}^{*}\right)^{2}+\left(b_{2}^{*}-b_{1}^{*}\right)^{2}+\left(L_{2}^{*}-L_{1}^{*}\right)^{2}}
$$

The lower the value of $\mathrm{DE}$, the shorter the vector, translating into a closer colour match to the platinum standard. The platinum standard values of $\mathrm{a} 1^{*}=0.3, \mathrm{~b} 1^{*}=3.4$ and $\mathrm{L} 1^{*}=82.3$ are indicative of the warm grey white of platinum. The whiteness of pure silver, at $L^{*} 95.8$ with little or no red/green $\left(a^{*}-0.7\right)$ or blue/yellow $\left(b^{*} 5.3\right)$ components is not the colour objective. MacCormack and Bowers have noted the ability of a human eye to discern approximately $1 \mathrm{DE}$ unit [7].

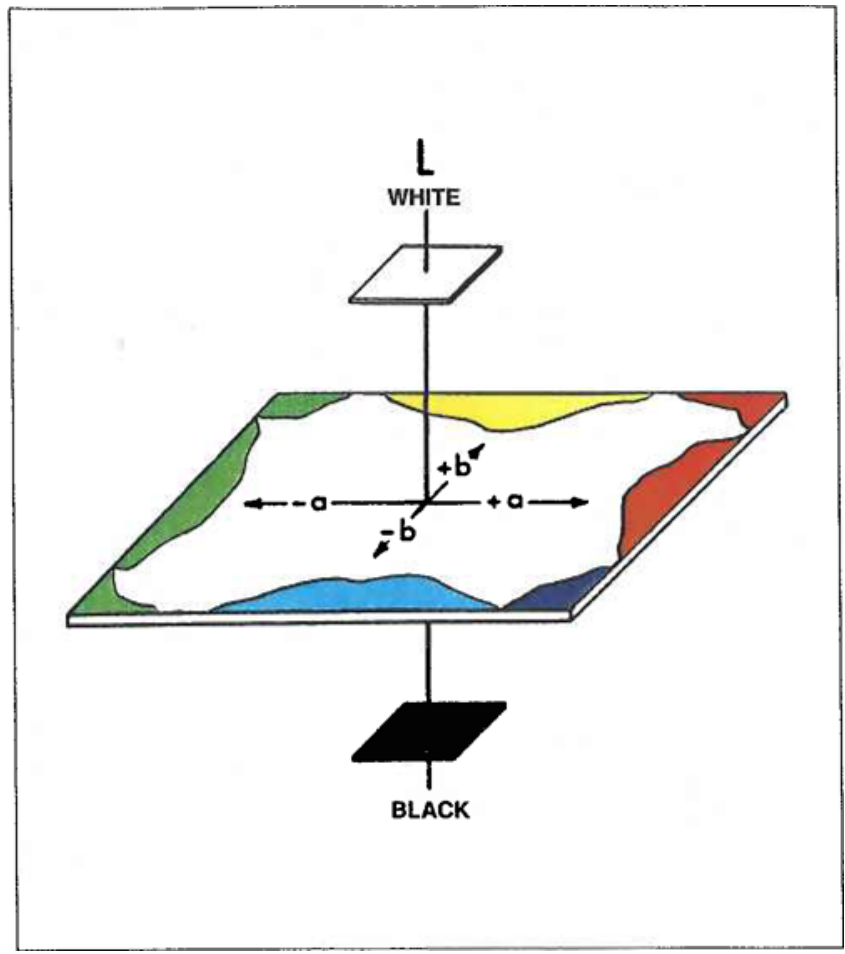

Figure 2

\section{CIELAB colour coordinate system for objective} quantification of colour (from [G])

\section{Hardness Determination}

Hardness or resistance to indentation was measured throughout experimentation on the Vickers hardness scale (HV). This indirect reading method allows for examination of the hardness indentation quality to ensure accuracy with variable low loading weights minimizing any anvil effect. Cast hardness tests employed $3 \mathrm{~mm}$ investment cast wafers ground flat to a 600 grit finish. Wrought hardness tests on rolled or annealed samples utilized varying thicknesses of shear cut coupons. Any cutting burrs were ground from exposed edges. Moderate as-cast or annealed hardness between 140 and $180 \mathrm{HV}$ ensures adequate wear resistance for jewellery applications. Hardness less than $120 \mathrm{HV}$ gives noticeable susceptibility to damage. Hardness above $200 \mathrm{HV}$ is usually accompanied by an increase in difficulty with fabrication. 


\section{Melting Range Determination}

Direct thermal analysis of $200 \mathrm{~g}$ samples induction melted in a clay graphite crucible surrounded by insulating material allowed for temperature descents at a rate of $1^{\circ} \mathrm{C}$ per second. A plot of temperature descent versus time, depicted in Figure 3, allowed for determination of the liquidus and solidus by virtue of a change in cooling rate or slope of the cooling curve.

This graphic method of estimation worked best with distinct slope changes. Poor delineation of the solidus sometimes occurred. Arbitrary targeting of $1100^{\circ} \mathrm{C}$ as the maximum desirable liquidus was based on two significant limitations. Above this temperature, application of common gypsum investment casting techniques becomes precarious. Molten metalgypsum reactions produce detrimental sulphur dioxide with increasing potential for gas porosity [8]. Additionally, the superheat required for continuous casting of metals with a liquidus above $1100^{\circ} \mathrm{C}$ challenges conventional melting equipment and results in rapid deterioration of crucible and mould materials such as graphite.

\section{Tensile Strength Data \\ Determination}

All testing was conducted on a MONSANTO type $\mathrm{W}$ tensile tester. As-cast properties of yield strength, ultimate tensile strength and percentage elongation were derived from Hounsfield type 'dumbell' samples of $50 \mathrm{~mm}$ diameter $25 \mathrm{~mm}$ long gauge length. Wrought tensile samples were stamped from rolled strip of $0.30 \mathrm{~mm}$ thickness annealed at $800^{\circ} \mathrm{C}$. Geometry closely approximated ASTM E8-89 specification with a $1 / 4$ inch shoulder radius, 1 inch gauge length and $3 / 8$ inch width. Values for yield strength (YS) and ultimate tensile strength (UTS) were expressed in ksi or pounds per square inch (psi) x 1000 . A lower yield strength was indicative of greater ease of plastic deformation required for formability.

The greater the range between the ultimate tensile strength and yield strength, the greater the latitude with deformation processes. Likewise, a high percentage elongation implies greater ductility prior to fracture.

\section{Cold Work Schedule Methodology}

Viability of cold work was assessed by starting with induction melted static cast ingots approximately $50 \times 16 \times 300 \mathrm{~mm}$ in size. This volume represented about 750 grams of material. The ingots were subjected to rolling on an $8 " \times 8 "$ mill to the point of edge cracking. The final thickness was recorded prior to annealing procedures by torch or box furnace with a water quench. Cold rolling reductions to the limit of material plasticity with intermediate anneals continued until the final $0.30 \mathrm{~mm}$ thickness was achieved. Final annealing was accomplished through a controlled nitrogen-hydrogen atmosphere furnace at a fixed

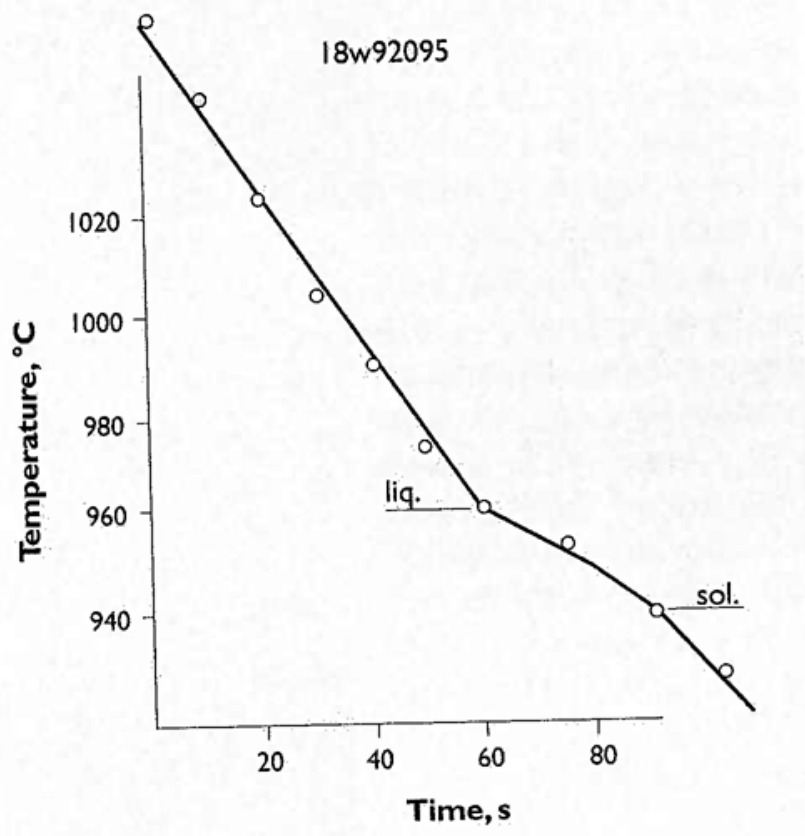

Figure 3

Typical thermal analysis plot of temperature descent versus time

belt travel speed at a temperature of $800^{\circ} \mathrm{C}$. Material that did not withstand an initial cold roll thickness reduction of $40 \%$ without substantial edge cracking or fracture was considered unsuitable for commercial processing.

Quantification of relative work hardening was possible by noting the percentage reduction limits and resultant hardness for a wide range of materials. 


\section{Investment Cast Form Filling Evaluation}

A sample of fixed, challenging geometry, depicted in Figure 4, was employed. The grid pattern of $1 \mathrm{~mm}$ diameter wire measured $9 \mathrm{~cm}$ high by $3.8 \mathrm{~cm}$ wide. Form filling performance was evaluated based on the percentage of total grid area filled by the cast metal. A fixed quantity of $200 \mathrm{~g}$ was induction melted with immersion pyrometer temperature measurement and a protective nitrogen gas cover. Superheat was maintained at $100^{\circ} \mathrm{C}$ above the liquidus. The sample orientation was fixed with respect to the rotation axis of the centrifugal caster.

\section{Fire-Cracking Resistance}

Wrought, annealed strip stock at $2 \mathrm{~mm}$ thickness was subjected to stamping operations to provide a constant geometry and hoop stress. A 2" diameter blank was drawn into a thimble of 1 "length with a $3 / 4 "$ opening. Figure 5 depicts a stamped sample and test failure. The fire-cracking has been emphasized with die penetrant. Heating by torch or furnace to less than $600^{\circ} \mathrm{C}$ produced massive longitudinal fire-cracking fractures if a composition was susceptible. No fracture was indicative of immunity or diminished sensitivity $[9,10]$.

Figure 4

Investment cast form filling grid wax pattern

\section{Nickel Allergy Testing}

The standard European DMG spot test was employed [11]. This methodology has acknowledged limitations producing consistent indications of potentially allergenic nickel content caused by the great variety of surface preparations employed with commercial jewellery products.

This limitation was surmounted with laboratory tests. A cotton swab with dimethylgloximine and ammonia was rubbed on a 600 grit ground and washed coupon surface. A colour change to pink or red on the test spot was indicative of nickel leaching and represented a test failure. No reaction or colour change indicated retention of the nickel content. If the nickel content of the alloy did not react with the DMG, it is presumed to remain inert towards common skin excretions, thus minimizing any allergenic reaction. The method remains a quick simple technique for considering a complex îssue.

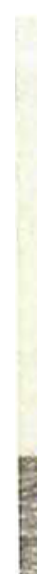

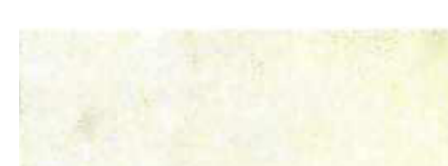




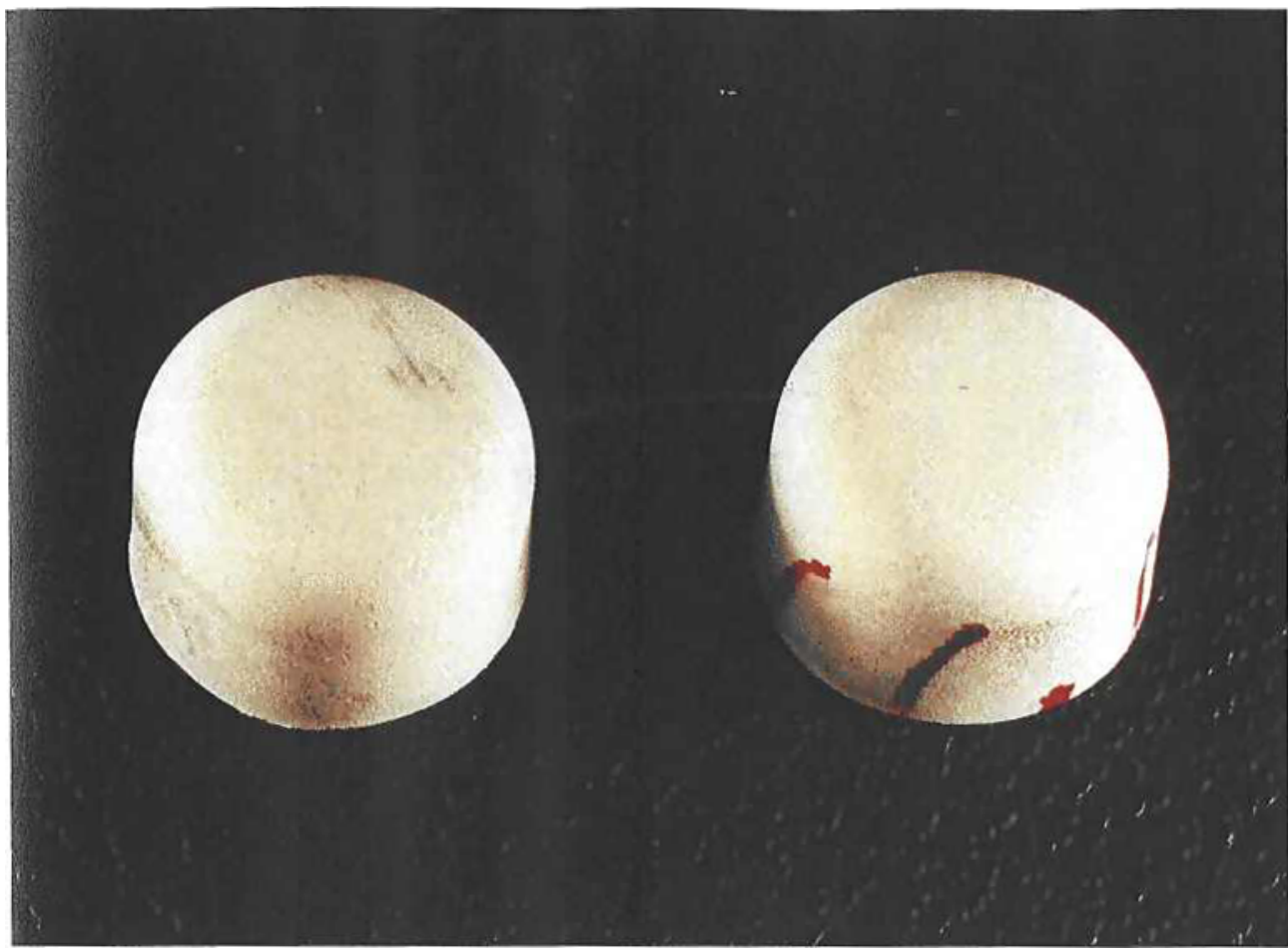

Figure 5

Fire cracking emphasized with red die penetrant to enhance large longitudinal split

\section{NICKEL WHITE GOLD PROPERTIES}

As a standard for comparison, the physical properties and characteristics of nickel white golds were first determined. Sample formulas were experimental or corresponded to various commercial materials and products available in the USA and Canada. This group of materials had a number of positive features which included low cost, reasonable corrosion resistance, suitability for rhodium plating, the ability to be investment cast and availability in sheet or wire form.
Their disadvantages included rapid work hardening requiring extensive annealing, excessive cast hardness, poor colour match with platinum in the 10 or 14 carat range and a tendency to fire-crack. Interpretation and comparison of data was facilitated by computing the ratio of copper to nickel in the various formulations. Table 1 summarizes the compositions for 10 carat nickel white golds together with the corresponding colour difference vector (DE), as-cast tensile strength (UTS) and yield strength (YS), percentage elongation, liquidus (Liq) and cast hardness (HV).

Table 1

10 carat nickel white gold test compositions and summary of physical properties

\begin{tabular}{c|ccc|c|cccccc} 
Alloy No. & Ni & $\mathbf{C u}$ & $\mathbf{Z n}$ & $\mathbf{C u}: \mathbf{N i}$ & DE & UTS & YS & $\begin{array}{c}\% \\
\text { Elong. }\end{array}$ & $\begin{array}{l}\text { Liq. } \\
\left({ }^{\circ} \mathbf{C}\right)\end{array}$ & HV \\
\hline 10W005 & 10.3 & 37.0 & 11.0 & $3.58: 1$ & 5.9 & 54.1 & 24.7 & 50 & 1042 & 120 \\
10W004 & 12.4 & 41.6 & 4.3 & $3.35: 1$ & 5.6 & 66.1 & 28.1 & 44 & 1028 & 133 \\
10W525 & 13.9 & 36.4 & 8.1 & $2.62: 1$ & 6.5 & 65.8 & 29.6 & 41 & 1018 & 141 \\
10W001 & 19.2 & 32.1 & 7.1 & $1.67: 1$ & 4.5 & 72.7 & 35.4 & 45 & 1087 & 147 \\
10W083 & 20.0 & 25.2 & 13.1 & $1.26: 1$ & 2.9 & 61.1 & 41.3 & 19 & 1049 & 163
\end{tabular}


Table 2

14 carat nickel white gold test compositions and summary of physical properties

\begin{tabular}{|c|c|c|c|c|c|c|c|c|c|c|c|}
\hline Alloy No. & $\mathbf{N i}$ & $\mathrm{Cu}$ & $\mathbf{Z n}$ & $\mathrm{Cu}: \mathrm{Ni}$ & $D E$ & UTS & YS & $\begin{array}{c}\% \\
\text { Elong. }\end{array}$ & $\begin{array}{l}\text { Liq. } \\
\left({ }^{\circ} \mathrm{C}\right)\end{array}$ & HV & $\begin{array}{l}\text { Figure } \\
\text { Symbol }\end{array}$ \\
\hline 14W007. & 7.2 & 26.4 & 8.1 & $3.69: 1$ & 7.1 & 51.4 & 27.5 & 35 & 994 & 128 & $\diamond$ \\
\hline 14W006 & 8.9 & 29.7 & 3.1 & $3.34: 1$ & 6.9 & 61.2 & 34.0 & 48 & 995 & 151 & a \\
\hline $14 W 525$ & 9.9 & 26.0 & 5.8 & $2.62: 1$ & 6.5 & 68.3 & 40.8 & 34 & 994 & 155 & $\otimes$ \\
\hline $14 W 003$ & 10.4 & 24.4 & 6.9 & $2.35: 1$ & 6.2 & 67.4 & 42.3 & 44 & 977 & 143 & $\diamond$ \\
\hline $14 \mathrm{~W} 002$ & 13.7 & 21.7 & 6.2 & $1.58: 1$ & 5.3 & 68.1 & 43.2 & 45 & 995 & 160 & $\square$ \\
\hline $14 W 075$ & 14.0 & 18.0 & 9.7 & $1.28: 1$ & 3.9 & 68.8 & 47.0 & 40 & 981 & 164 & $\bullet$ \\
\hline
\end{tabular}

Similar tabulations for 14 carat white gold formulations are shown in Table 2.

Comparison of the physical attributes shown in Table 2 with the corresponding copper-nickel ratio led to Figures 6 to 9.

Results are essentially similar for both 10 and 14 carat nickel white golds. The increasing length of the colour vector $(\mathrm{DE})$ with increasing copper nickel ratio confirms that reflectivity suffers as copper additions are made at the expense of nickel (Fig. 6). Low values of $\mathrm{DE}$ associated with higher nickel additions are most desirable. Increasing nickel additions necessary to impart a desirable colour produce higher cast hardness (Fig. 7).

Likewise, elevated nickel additions cause high yield and tensile strengths (Fig. 8). Finally, hindering manufacturing procedures such as investment casting or continuous casting, the whitest nickel golds have the highest liquidus temperatures. This is expressed in Figure 9, where the ratio of nickel to zinc illustrates a direct relationship with liquidus temperature. Zinc additions form an integral part of nickel white gold alloys. They act as a deoxidizer, investment wetting agent, liquidus depressor and whitener. Excessive levels cause sensitivity to fire-cracking, impaired physical properties and difficulties with recycling. Even large additions will not overcome the basic limitations of the alloy system.

A similar summary of attributes for 18 carat materials seemed redundant given the confirmation of properties with 10 and 14 carat formulations. Clearly, within the nickel white gold family, desirable properties are in conflict with each other. Additions of one element to enhance one property, may cause impairment of another.

This conflict has been noted by many authors in the past. The range of compositions detailed merely illustrate the inherent tradeoffs and form a standard for comparison with other material formulations.

\section{ALTERNATIVE ALLOY SYSTEMS}

Given the work of MacCormack and Bowers in quantifying gold decolourizing efficiency, more study of iron additions seemed promising. They ranked iron as the second most effective bleaching agent of gold behind palladium, but ahead of nickel on a weight basis.

Gold content of 14 carat was selected as a starting point since a significant amount of white materials are employed as 4 prong settings for diamonds in ladies' rings. Most previous work had been completed for 18 carat materials only, suggesting exploration in a lower carat alloy would be novel.

\section{IRON USAGE IN WHITE GOLDS}

Use of iron as a primary whitener with palladium revealed several shortcomings. A formulation of $18 \%$ iron, $15.2 \%$ copper and $8.6 \%$ palladium exhibited 


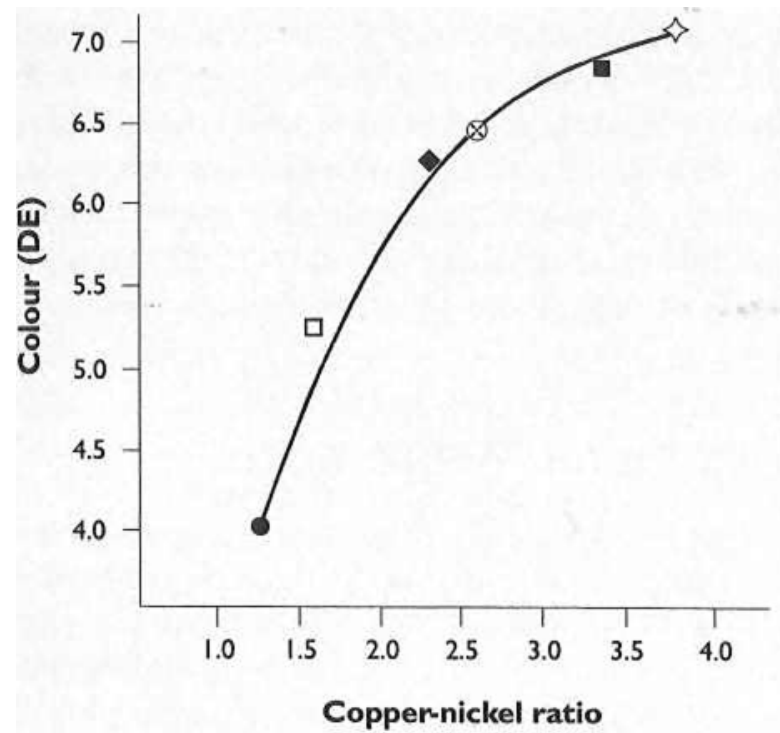

Figure 6

14 carat white gold: Copper-nickel ratio versus colour vector length

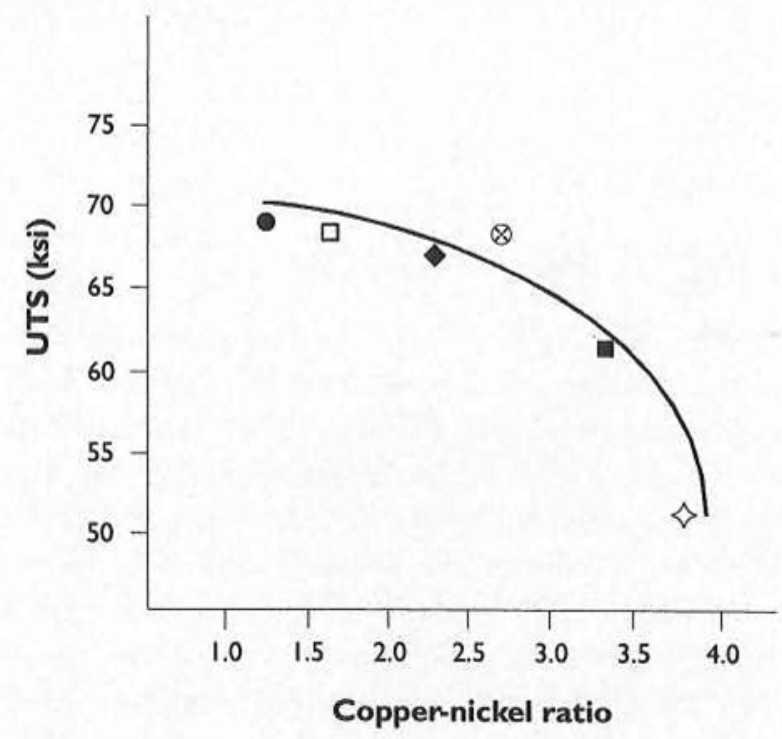

Figure 8

14 carat white gold: Copper-nickel ratio versus tensile strength (UTS)

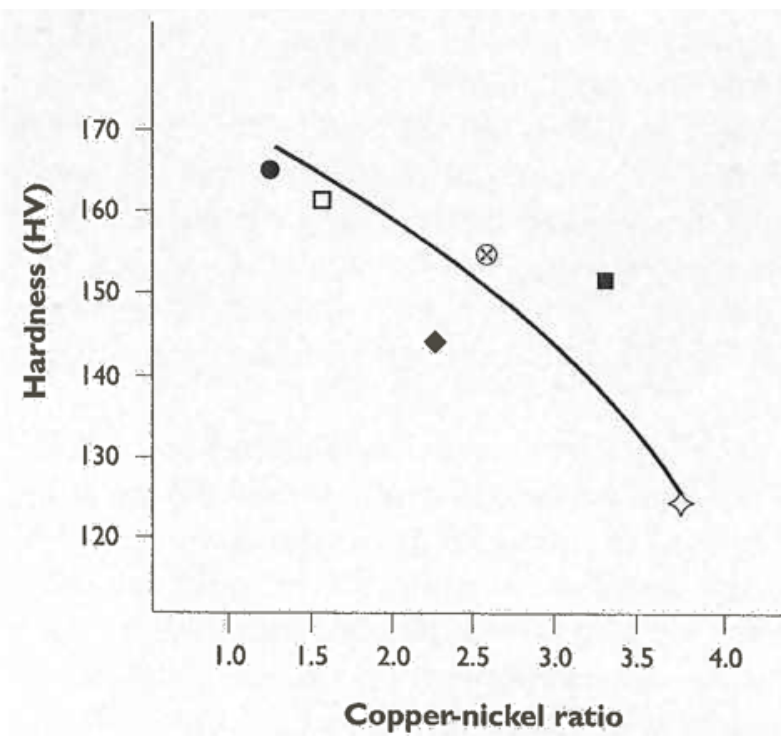

Figure 7

14 carat white gold: Copper-nickel ratio versus cast Vickers hardness

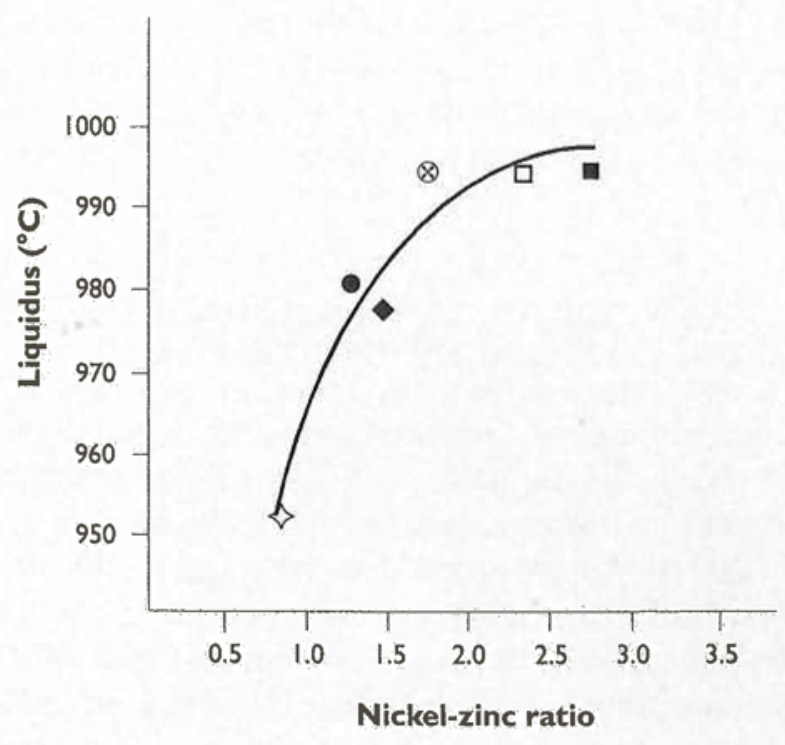

Figure 9

14 carat white gold: Nickel-zinc ratio versus liquidus temperature 
a dark grey colour, but suffered from excessive volatilization (as sparks), high hardness $(232 \mathrm{HV}$ ) and only $50 \%$ reduction on initial cold working. Use of $4.2 \%$ iron as a secondary whitener with $16.7 \%$ palladium and $20.8 \%$ copper yielded a respectable colour that would not cold roll. Switching to palladium as the primary whitener, $18 \%$ in combination with $12 \%$ copper and $12 \%$ iron still exhibited marginal formability with a heavy brown oxide during investment casting.

The combination of palladium, nickel and iron yielded reasonable colour with formability exceeding $60 \%$ on cold rolling. Formulations such as $25 \% \mathrm{Pd}$ $10 \% \mathrm{Ni}-6.7 \% \mathrm{Fe}$ still suffered from oxidation problems. Despite utilizing high purity electrolytic iron powder, added slowly in copper wrapped foil packets, dissolution in the gold alloys was sluggish. Ternary preparations of palladium-nickel-iron and palladiumcobalt-iron were melted into shot form in an attempt to minimize the iron volatilization problem.

This technique was not a complete solution. Even alloying a 10 carat white gold with $16.7 \%$ palladium, $20.9 \%$ copper and $4.2 \%$ iron did not eliminate volatile sparking. Detailed testing of all physical properties and attributes was not undertaken because of the unmanageable response to conventional processing methods. Predictably, gold assays for white materials using iron-based bleaches were erratic and often unacceptably high compared to conventional tolerances. We concluded that iron usage offered no gains that appeared to be commercially viable.

\section{COBALT USAGE IN WHITE GOLDS}

Exploration of cobalt usage largely confirmed the observations of O'Connor. Sufficient cobalt to whiten gold-copper materials pushed the liquidus in excess of $1250^{\circ} \mathrm{C}$, implying poor bleaching action. Dissolution of cobalt was very sluggish, confirming marginal solubility. Combinations of $6.5 \%$ cobalt with $20 \%$ palladium and $14.7 \%$ copper exhibited good cold working ( $90 \%$ reduction), mediocre colour, elevated cast hardness $(286 \mathrm{HV})$ and a liquidus in excess of $1110^{\circ} \mathrm{C}$. Use of palladium, nickel and cobalt produced a very hard material ( $310 \mathrm{HV}$ ), with poor cold work reduction (less than $50 \%$ ) and the persistent elevated liquidus. Combinations of silver, palladium, nickel and cobalt produced a reasonable cast hardness of $175 \mathrm{HV}$, suitable workability (60\% reduction during cold working), but a yellowed colour (DE 10). Use of cobalt as a primary whitener was rejected for a number of reasons: poor solubility, poor bleaching capabilities, minimal improvement in physical properties and elevation of the formulation liquidus.

\section{BASE METAL WHITE GOLDS}

Having rejected many novel formulations containing iron or cobalt, the use of these elements to enhance existing nickel-based white golds was studied. Direct substitution of cobalt as a secondary whitener for copper produced interesting results. Utilizing the previously noted 14W/525 formulation (Table 2), replacement of $6.5 \%$ copper with cobalt caused the liquidus to increase $40^{\circ} \mathrm{C}$ while the colour degraded from DE 6.5 to 9.4 . The alloy yellow component $\mathrm{b}^{*}$ actually increased from 6 to 11.3 with additions of greyish white cobalt for red copper. Substituting $6.5 \%$ cobalt and $2.0 \%$ iron for the zinc content in the 14W075 alloy previously discussed, caused the hardness to increase from 165 to $225 \mathrm{HV}$ while degrading the colour and cold work reduction to $20 \%$. Improvement of existing commercial materials with additions of iron or cobalt did not appear promising.

\section{BLENDED WHITE GOLDS}

As noted in the first review of white golds, Susz and Linker advocated the application of blended nickel and palladium white golds [5]. They maintained the use of proportions of nickel-copper-zinc materials with silver-palladium alloys to achieve properties that represented a compromise between the two. Attempts by O'Connor to reduce the hardness of nickel white golds with palladium additions were unsuccessful. He noted an increase in the liquidus with improved whiteness by dual element bleaching, but no reduction in the extreme hardness induced by nickel. Despite these predictions, some study was warranted.

Starting with a 14 carat nickel white gold formulation around the commercial average, palladium was 
substituted for copper. The resulting formulation, $11.5 \% \mathrm{Ni}-10.2 \% \mathrm{Cu}-5 \% \mathrm{Zn}-15 \% \mathrm{Pd}$, exhibited excellent colour, a $90 \%$ reduction during initial cold working, but an elevated cast hardness of $257 \mathrm{HV}$. Attempts to lower the hardness by adding $4.5 \%$ additional $\mathrm{Cu}$ at the expense of $1.5 \% \mathrm{Ni}$ and $3 \% \mathrm{Zn}$ were successful (206 HV), to the detriment of colour.

Cobalt additions, as suggested by O'Connor, to lower hardness while preserving colour were unsuccessful. Use of $2 \%$ cobalt, substituted for $1.5 \% \mathrm{Ni}$ and $0.5 \% \mathrm{Zn}$ caused the hardness to increase to $280 \mathrm{HV}$. Colour remained excellent at $\mathrm{DE}=1.6$. Increasing the palladium and copper content $(18 \% \mathrm{Pd}$ $11.9 \% \mathrm{Ni}-11.9 \% \mathrm{Cu}$ ) to decrease hardness was successful ( $198 \mathrm{HV})$, but caused the liquidus to rise beyond the $1100{ }^{\circ} \mathrm{C}$ target.

Exploration of silver usage was not fruitful. A combination of $21.7 \% \mathrm{Ag}, 10 \% \mathrm{Ni}$ and $10 \% \mathrm{Pd}$ possessed a suitably low cast hardness (157 HV), good cold working response ( $90 \%$ thickness reduction), a reasonably white colour, but too high a liquidus. Lowering the palladium content to $5 \%$, while increasing the nickel content to $15 \%$, lowered the cast hardness to $131 \mathrm{HV}$, but generated an unacceptable colour.

Copper additions $(16.7 \% \mathrm{Ag}-10 \% \mathrm{Pd}-7.5 \% \mathrm{Ni}-$ $7.5 \% \mathrm{Cu}$ ) only served to increase the cast hardness to $280 \mathrm{HV}$. No manipulations within the system of elements appeared to satisfy all material property requirements without some significant compromise. Essentially palladium-silver additions to nickel-copper-zinc white golds cause the liquidus to increase.

If the initial liquidus at 18 carat is strongly influenced by the gold-nickel binary minimum, movement upwards from $930^{\circ} \mathrm{C}$ is feasible while maintaining conventional manufacturing methods. With bright nickel white 10 or 14 carat commercial materials, the liquidus rises from 1070 and $1000^{\circ} \mathrm{C}$ respectively. Minor additions of palladium-silver do not decrease the hardness and whiten enough to justify the increase in liquidus temperature. When the cost of palladium usage is combined with the presence of sufficient nickel to fail DMG testing, these materials lose still more appeal.

While acknowledging that many commercially employed formulations rely on this set of compromises, we elected to explore other avenues to avoid the inevitable tradeoff of blended white golds.

\section{NICKEL-FREE WHITE GOLDS}

Considering the lack of promising results with previous study of base metal bleaches such as iron and cobalt, nickel-free formulations focussed on the precious metal bleaches silver and palladium.

\section{SILVER USAGE IN WHITE GOLDS}

Silver is acknowledged as a poor bleach of gold. At $25 \%$ additions by weight required for 18 carat materials, it does not sufficiently bleach the characteristic yellow of gold. Only at the 10 or 14 carat gold content, can sufficient additions begin to instill a white hue. Regrettably, the colour coordinates of commercially pure silver $\left(L^{*} 95.8, a^{*}-0.7, b^{*} 5.3\right)$ describe a bright pure metallic white, not the warm greyish white of platinum. Considerable separation between the colours is indicative of a DE value of 13.7. Full bleaching of gold by silver does not result in the desired shade. Furthermore, elevated silver levels create susceptibility to corrosion through sulphur tarnishing reactions [12], As an example, a 14 carat alloy with maximum silver bleaching additions of $39.7 \%$ and $2 \%$ zinc has colour coordinates of $L^{*} 95.5$, $a^{*}-1.6, b^{*} 6.6$. These closely mimic silver white, not platïnum grey $(\mathrm{DE}=13.7)$. Additionally, hardness, at $60 \mathrm{HV}$, was too low for applications requiring any strength or wear resistance. Similar results occur in 10 carat silver gold materials.

\section{PALLADIUM USAGE IN WHITE GoldS}

To overcome the limitations utilizing silver for bleaching of gold, substantial palladium is incorporated in commercial materials. The gold-silver-palladium family of white golds was considered as a separate division in the first segment of documentation. Positive features include an excellent colour match with adequate palladium additions, low as-cast hardness, superior ductility, good cold working properties, no susceptibility to fire-cracking, good tarnish resistance and ease of recycling. These desirable attributes are offset by the expensive nature of the alloying constituents and the elevated liquidus values $\left(1100^{\circ} \mathrm{C}\right)$ impairing the application of investment casting or continuous casting 
procedures. Significant modifications are required to ensure these materials can be mass produced as economically as nickel white golds. This breakthrough will isolate cost discrepancy to their intrinsic value only, rather than exaggerate their differences by virtue of labour intensive manufacturing procedures.

Within the conventional gold-silver-palladium ternary relationship, a binary minimum or liquidus depressing interaction does not exist between the elements. The significant quantities of palladium required to provide a colour match with platinum and counteract the tarnishing tendencies of silver mean liquidus values in excess of $1100^{\circ} \mathrm{C}$. Figure 10 summarizes this relationship. A 14 carat alloy with $21.4 \%$ silver, $12 \%$ palladium and $8.3 \%$ copper has a DE value of 12. The colour coordinates of $L^{*} 72.7, a^{*} 1.4$ and $b^{*} 10.6$ translate into the dark grey characteristic of many palladium bleached white golds. The $L^{*}$ value is much lower than typical nickel white golds $\left(\mathrm{L}^{*} 80\right.$ 82) Low hardness of $127 \mathrm{HV}$, good cold workability of $90 \%$ initial thickness reduction and a liquidus of $1083^{\circ} \mathrm{C}$ cannot offset the colour deficiency.

There is considerable scope for alloy design within the gold-copper-palladium system. This may seem strange that a red element such as copper holds greater potential than a white element such as silver. The liquidus surface of their ternary relationship, depicted in Figure 11, reveals domination by the goldcopper binary minimum. This provides considerably more flexibility for alloy design and compromise. At the 10 carat level, for example, approximately $30 \%$ palladium can be employed for bleaching purposes while remaining within the $1100^{\circ} \mathrm{C}$ liquidus target. With the gold-silver-palladium ternary system, only $9 \%$ palladium can be employed. Furthermore, the gold-copper ordering reaction provides a hardening mechanism to this family of materials, whereas the complete solid solubility predominant with gold-silver-palladium provides no such capabilities. This alloy system has been studied extensively for dental and contact applications [13].

\section{Carat Palladium White Golds}

Fulfillment of a colour match with platinum established the required quantity of palladium additions. The formulation of $20 \%$ palladium and $21.7 \%$ copper possessed a high quality colour $(\mathrm{DE}=2.3)$ with a $1100^{\circ} \mathrm{C}$ liquidus and a hardness of $172 \mathrm{HV}$. Lower

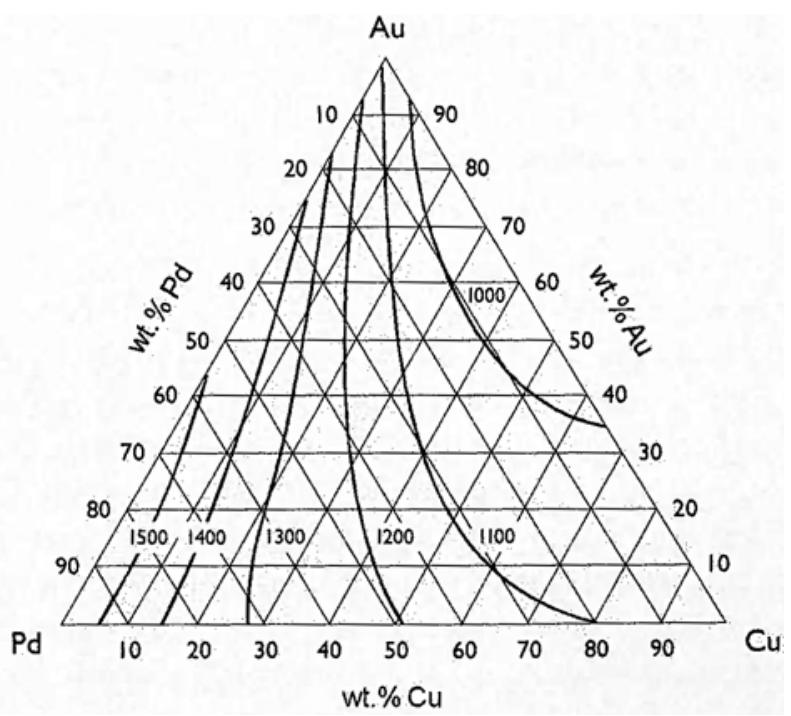

Figure 11

The gold-copper-palladium ternary liquidus diagram illustrating considerable palladium bleaching additions without exceeding $1100^{\circ} \mathrm{C}$ 


\begin{tabular}{|c|c|c|c|c|c|c|c|}
\hline \multicolumn{4}{|c|}{ Formulation } & $\begin{array}{c}\text { Hardness } \\
\text { (HV) }\end{array}$ & $\begin{array}{l}\text { Liquidus } \\
\left.\text { ( }{ }^{\circ} \mathrm{C}\right)\end{array}$ & $\begin{array}{l}\text { Colour } \\
\text { (DE) }\end{array}$ & \multirow[t]{8}{*}{$\begin{array}{l}\text { Properties of } 14 \text { carat } \\
\text { palladium white golds }\end{array}$} \\
\hline $20 \% \mathrm{Pd}$ & $21.7 \% \mathrm{Cu}$ & & & 172 & 1100 & 2.3 & \\
\hline $20 \% \mathrm{Pd}$ & $19.7 \% \mathrm{Cu}$ & $2 \% \mathrm{Zn}$ & & 322 & - & - & \\
\hline $20 \% \mathrm{Pd}$ & $14.7 \% \mathrm{Cu}$ & $7 \% \mathrm{Ag}$ & & 160 & 1115 & 4.8 & \\
\hline $20 \%$ Pd & $14.7 \% \mathrm{Cu}$ & $5 \% \mathrm{Ag}$ & $2 \% Z n$ & 178 & 1075 & 3.2 & \\
\hline $20 \%$ Pd & $14.7 \% \mathrm{Cu}$ & $5 \% \mathrm{Ag}$ & $2 \% \ln$ & 165 & 1092 & 6.2 & \\
\hline $20 \%$ Pd & $14.7 \% \mathrm{Cu}$ & $5 \% \mathrm{Ag}$ & $2 \% \mathrm{Sn}$ & 175 & 1077 & 7.3 & \\
\hline $20 \% \mathrm{Pd}$ & $14.7 \% \mathrm{Cu}$ & $5 \% \mathrm{Ag}$ & $2 \%$ Co & 167 & 1105 & 9.3 & \\
\hline
\end{tabular}

palladium additions with the silver-copper eutectic ratio, encompassed in the formulation $25.7 \%$ silver, $10 \%$ copper, $5.9 \%$ palladium, had an unsuitable yellowish shade.

Increasing the palladium content to $12 \%$ while maintaining the silver-copper eutectic ratio provided an excellent $90 \%$ reduction through cold working, a liquidus of $1083^{\circ} \mathrm{C}$, but poor colour as indicated by a $D E$ value of 12 . Attempts to establish a suitable colour at the $12 \%$ palladium content by blending other whiteners such as zinc or indium with small silver additions produced only poor pinkish colours or minimal formability. Bleaching to a suitable white colour seemed dependent on the presence of $20 \%$ palladium.

Efforts were focussed on improving the properties of the $20 \%$ palladium $21.7 \%$ copper formulation that exhibited a quality colour. Liquidus depression below $1100^{\circ} \mathrm{C}$ was considered critical to allow for investment casting free from sulphur dioxide gas generation and to provide latitude for successful continuous casting with graphite crucibles. Unfortunately, the alloy behaved very similarly to an ordered high carat red gold, exhibiting sensitivity to temperature depressing additions. Zinc usage at only $2 \%$ elevated the cast hardness from 172 to $322 \mathrm{HV}$ with a corresponding dramatic decrease in formability.

At the expense of a $15^{\circ} \mathrm{C}$ elevation of the liquidus, substituting $7 \%$ copper with silver improved the cold work properties from 60 to $90 \%$ initial thickness reduction while reducing the cast hardness from 172 to $160 \mathrm{HV}$. Significantly, the silver additions also reduced the alloy sensitivity allowing evaluation of liquidus depression with $2 \%$ additions of indium, tin, zinc or cobalt. Results are summarized in Table 3.

Clearly, $2 \%$ additions of zinc cause the least impairment of colour and provide the most significant lowering of the liquidus while maintaining reasonable hardness. Furthermore, zinc is a suitable deoxidizer while enhancing wetting action and fluidity during investment casting $[15,16]$. After identification of zinc as the most suitable temperature depressor, more detailed testing at varying levels indicated that additions between 1 and $2 \%$ optimized properties. At the $4 \%$ level, liquidus depression was significant $\left(1056^{\circ} \mathrm{C}\right)$, but ductility was non-existent. Overall, properties were within the original standards for commercial viability, worthy of detailed comparison to conventional nickel white golds in the next section.

\section{Carat Palladium White Golds}

Extension of the detailed formulation strategies from 14 carat to 10 carat white golds proved successful. It is customary with nickel white golds and very convenient to employ a base metal alloy of common elemental ratios simply added to the appropriate quantity of gold to create the desired caratage. This allows for collection of mixed caratage, common alloy addition production scraps with little concern for anything other than gold content. Additions of gold to raise caratage - or base metal alloy to lower it - produce the requisite elemental composition at the appropriate caratage. With the elevated palladium content required to impart the desired white platinum colour, this strategy acquires greater significance. Eliminating the need for different base metal formulations of incompatible 
palladium content for each carat would minimize con-sumption of the valuable alloying element.

Thermal and alloying behavior are virtually identical between 10 and 14 carat. Alloying additions increase in quantity by $40 \%$ between the carats to provide a formulation as follows: $28.0 \%$ palladium, $20.5 \%$ copper, $8.4 \%$ silver, $1.4 \%$ zinc. The liquidus of $1091{ }^{\circ} \mathrm{C}$ is within the $1100{ }^{\circ} \mathrm{C}$ limit. As-cast hardness of $161 \mathrm{HV}$ and $40 \%$ elongation indicate suitable formability. Colour is an excellent match to platinum at $\mathrm{DE}=3.5$. Again, detailed comparison of all attributes to nickel white golds is a worthwhile exercise.

\section{Carat Palladium White Golds}

Extension of the alloy design principles employed with 10 and 14 carat materials towards 18 carat compositions is seldom possible. This principle affects common yellow and nickel white golds. Elevated copper to silver ratios of the order of $5: 1$ at 10 or 14 carat produce reddish golds when applied to 18 carat. Likewise, high copper to nickel ratios required to ensure formability and depress the liquidus of conventional white golds provide too low a nickel bleach level resulting in a poor reddish shade at the 18 carat level.

The same limitations occur if the successful palladium-copper-silver-zinc formulation from the 10 and 14 carat white golds is employed at the 18 carat level. Any use of silver impairs the high carat colour. Palladium levels around $15 \%$ are required to provide adequate bleaching of the reddish copper hue. By virtue of the dominant gold-copper relationship, the liquidus at $1074^{\circ} \mathrm{C}$ remains manageably low for the respectable colour ( $\mathrm{DE}=4.3$ ). Palladium-silver-copper-zinc materials of similar colour possess a liquidus in excess of $1200^{\circ} \mathrm{C}$. While colour enhancement at 18 carat is less pronounced than with the 10 and 14 carat materials, melting range, cast hardness and physical properties compare favourably with nickel white golds.

\section{COMPARISON BETWEEN COMMERCIAL NICKEL WHITE GOLDS AND EXPERIMENTAL PALLADIUM MATERIALS}

The data previously summarized in Tables 1 and 2 for conventional 10 and 14 carat nickel white golds was averaged for comparison to the most promising palladium white gold experimental materials. Results are best separated into the three common caratages for

\begin{tabular}{|c|c|c|c|}
\hline & Attribute & Ni-based & Pd-based \\
\hline & Colour difference (DE) & 5.1 & 3.5 \\
\hline & Liquidus $\left({ }^{\circ} \mathrm{C}\right)$ & 1045 & 1091 \\
\hline & Cast hardness (HV) & 141 & 161 \\
\hline & Cast tensile strength (UTS) & 63.9 & 72.7 \\
\hline & Cast yield strength (YS) & 31.8 & 52.1 \\
\hline & \% Elongation & 40 & 40 \\
\hline & Cold working properties & & \\
\hline & $\%$ Reduction / hardness & $\begin{array}{l}80 \% / 327 \\
83 \% / 330\end{array}$ & $\begin{array}{l}67 \% / 294 \\
88 \% / 301\end{array}$ \\
\hline Table 4 & Investment casting form fill & & \\
\hline 10 carat white gold & Percentage (liquidus $+100^{\circ} \mathrm{C}$ ) & 90 & 45 \\
\hline property comparison: & Fire-cracking tendency & high & immune \\
\hline $\begin{array}{r}28 \% P d-20.5 \% \mathrm{Cu}- \\
8.4 \% \mathrm{Ag}-1.4 \% Z \text { n versus } \\
\text { nickel-based materials }\end{array}$ & Nickel DMG test & failed & passed \\
\hline
\end{tabular}




\section{Table 5}

\begin{tabular}{|c|c|c|}
\hline Attribute & Ni-based & Pd-based \\
\hline Colour difference (DE) & 5.9 & 3.2 \\
\hline Liquidus $\left({ }^{\circ} \mathrm{C}\right)$ & 982 & 1094 \\
\hline Cast hardness (HV) & 150 & 161 \\
\hline Cast tensile strength (UTS) & 64.2 & 68.6 \\
\hline Cast yield strength (YS) & 39.1 & 45.1 \\
\hline \% Elongation & 41 & 38 \\
\hline \multicolumn{3}{|l|}{ Cold working properties } \\
\hline \% Reduction / hardness & $\begin{array}{l}80 \% / 302 \\
65 \% / 300\end{array}$ & $\begin{array}{l}78 \% \text { / } 285 \\
80 \% / 287\end{array}$ \\
\hline \multicolumn{3}{|l|}{ Investment casting form fill } \\
\hline Percentage (liquidus $+100^{\circ} \mathrm{C}$ ) & 40 & 62 \\
\hline Fire-cracking tendency & high & immune \\
\hline Nickel DMG test & failed & passed \\
\hline
\end{tabular}

14 carat white gold property comparison: $20 \% P d-14.7 \% \mathrm{Cu}-$ $6.0 \% \mathrm{Ag}-1.0 \% \mathrm{Zn}$ versus nickel-based materials

each of the two dominant gold bleaching elements (Tables 4 to 6). Interpretation of the various attributes follows from the discussion of experimental technique. Cold working studies are summarized by displaying the initial percentage reduction and subsequent hardness from rolling the cast ingot. Interme- diate wrought cold rolling reduction and resultant hardness provide quantification of overall formability performance.

Data for nickel-based 18 carat comparison was derived from a common formulation of $13.5 \%$ nickel, $8.5 \%$ copper and $3.0 \%$ zinc.

\begin{tabular}{|c|c|c|}
\hline Attribute & Ni-based & Pd-based \\
\hline Colour difference (DE) & 6.5 & 4.3 \\
\hline Liquidus $\left({ }^{\circ} \mathrm{C}\right)$ & 960 & 1074 \\
\hline Cast hardness (HV) & 235 & 167 \\
\hline Cast tensile strength (UTS) & 88.4 & 81.6 \\
\hline Cast yield strength (YS) & 72.6 & 64.4 \\
\hline \% Elongation & 29 & 35 \\
\hline \multicolumn{3}{|l|}{ Cold working properties } \\
\hline$\%$ Reduction / hardness & $\begin{array}{l}75 \% / 330 \\
75 \% / 366\end{array}$ & $\begin{array}{l}76 \% / 265 \\
85 \% / 272\end{array}$ \\
\hline \multicolumn{3}{|l|}{ Investment casting form fill } \\
\hline Percentage (liquidus $+100^{\circ} \mathrm{C}$ ) & 95 & 82 \\
\hline Fire-cracking tendency & high & immune \\
\hline Nickel DMG test & failed & passed \\
\hline
\end{tabular}

Table 6

18 carat white gold property comparison: $15 \% \mathrm{Pd}-7.0 \% \mathrm{Cu}$ $3.0 \% \mathrm{Zn}$ versus nickelbased materials 
As a family of materials, gold-palladium-copper white golds exhibit a number of positive attributes. They can be summarized as follows:

- suitable platinum white colour with adequate palladium additions,

- hard but ductile materials,

- good workability with lower cold worked hardness than nickel white golds,

- ease of recycling with minimal volatile additions,

- immunity to fire-cracking,

- good tarnish resistance from elevated palladium content,

- low enough liquidus for conventional manufacturing,

- no nickel content to promote allergenic activity.

The elevated liquidus temperatures of palladium white golds challenge standard melting equipment, particularly resistance type heating. With care and attention to procedures, good quality investment cast pieces can be achieved. Several test batches in each caratage produced castings with a varicty of cross sections and detail, free from sulphur dioxide gas porosity and significant shrinkage defects. The high cost of palladium bleaching additions remains the dominant drawback.

\section{ECONOMIC CONSIDERATIONS}

Given the ability to apply mass production technologies such as continuous casting and gypsum investment casting to palladium-copper white golds, they should have the same manufacturing costs as commercial nickel white golds. The additional intrinsic cost of palladium will continue to detrimentally influence total cost comparison.

Nickel white golds appear to remain the cheapest alloy formulations, if intrinsic cost is a dominant consideration. No other base metal bleach appears available to replace nickel for commercial usage. Formability and hardness limitations can be surmounted with inexpensive processing techniques. The issue of nickel dermatitis from white golds may achieve greater significance, particularly in Europe, in the near future. If nickel usage is banned, palladium-copper white golds appear feasible as replacement materials from a physical attributes perspective. With comparable hardness, improved colour and good strength, they are viable replacements for fasteners such as butterfly earring clasps, four prong settings or spring wire.

The reduced liquidus range of palladium-copper white golds over palladium-silver based materials is a technically significant advantage.

Blended white golds, combinations of palladiumsilver with nickel-copper-zinc, are midway on the intrinsic cost spectrum. They possess a compromise of properties, the presence of nickel but the usage of reduced palladium content. The primary bleaching action of nickel affords an intrinsic cost reduction by lower palladium content compared to the experimental formulations.

Mass production of low value items with the additional intrinsic cost of palladium additions would be difficult to justify. Special hand crafted jewellery or unique designs such as tube settings seem a more likely application for palladium white gold materials.

\section{FIELD TEST RESULTS}

Machining trials revealed that palladium-based white golds possess superior chip forming properties comparable to yellow gold. This made them easier to machine for seamless band applications. Tool chatter and wear was reduced without any specific additional lubrication or cooling. Field testing with bench jewellers produced a number of supportive observations. Palladium-based white golds drill easier than nickel bleached materials. Hand engraving and setting was easier to accomplish. Claws were formed and shaped for holding stones without failure or difficulty. Machine faceting of seamless bands did not reveal any appreciable difference in material performance compared to conventional materials.

Investment castings of the test palladium white golds could be hammer sized and filed very similarly to nickel materials. This implied they were more difficult to handle than yellow golds. Sizing operations of cutting and soldering were accomplished without incident. Grinding operations were executed similarly to nickel white golds. Final polishing operations produced high quality surface finish more easily than with nickel white golds. 
The palladium materials cut evenly without any smearing or comet tail type defects. Setting operations were a pleasure compared to conventional materials. Prongs could be bent easily and smoothly with no springback. Resetting or additional manipulation of the prongs did not result in the brittle fracture usual with nickel white golds. When a layer of rhodium plating was applied, a slight colour difference could be seen. While acknowledging the bright white colour of the palladium golds, the jewellers believed a final rhodium plate was still necessary. Reception to working with the experimental materials was generally positive.

\section{CONCLUSIONS}

Quantification of the physical attributes of nickel white golds highlighted the compromises inherent in the alloy system. Application of secondary whiteners such as iron or cobalt impart no significant improvements to their properties. Such base metal additions actually degraded properties or complicated manufacturing procedures. Nickel remains the least expensive commercially viable bleach of gold.

Formulations based upon palladium-copper-silver-zinc additions exhibit commercial viability, particularly in 10 and 14 carat gold. Eliminating the presence

\section{REFERENCES}

1. G. Normandeau, 'White Golds: A Review of Commercial Material Characteristics \& Alloy Design Alternatives', Gold Bull., 25(3), pp. 94-103, 1992

2. G. O'Connor, 'Improvement of 18 Carat White Gold Alloys' Gold Bull., 11(2), pp. 35-39, 1978

3. A. McDonald, G. Sistare, 'The Metallurgy of Some Carat Gold Jewellery Alloys', Gold Bull., 11(4), pp. 128-131, 1978

4. C. Susz, M. Linker, '18 Carat White Gold Jewellery Alloys', Gold Bull., 13(1), pp. 15-20, 1980 of nickel may have significant implications if future concerns about dermatitis translate into legislation banning use of the element. Attainment of design goals and comparative improvements in prop- erties such as colour, cold working performance, immunity to fire-cracking and tarnish resistance indicate potential for usage. A small sacrifice of elevated melting temperature that still allows for mass production methods such as investment or continuous casting reinforces viability. Field testing performance in a manu-facturing environment confirmed positive attributes. The issue of additional intrinsic cost from palladium usage remains dominant.

Blending of palladium and nickel white golds offers an opportunity to lessen the impact of palladium cost, but at the expense of other compromises in physical properties. While this compromise is the cornerstone of numerous commercial formulations in Europe, it was not studied in detail equivalent to the nickel-free materials. Opinion within the trade indicates that mass production applications employing white golds cannot bear the cost burden of palladium bleaching additions. Nickel white golds, while difficult to work compared to yellow materials, can be handled with minimum extra labour. Comparatively expensive hand worked custom jewellery items may be the primary application for palladium white golds.
5. G. O'Connor, 'Alloy Additions for 18 Carat White Gold Jewellery Alloys', Metals Technology, pp. 261266, 1979

6. R. German, M. Guzowski, D. Wright, 'The Colour of Gold-Silver-Copper Alloys', Gold Bull., 13(3), pp. 113-116, 1980

7. B. MacCormack, J. Bowers, 'New White Gold Alloys', Gold Bull., 14(1), pp. 19-24, 1981

8. D. Schneller, 'Sulphur Dioxide Porosity', American Jewellery Manufacturer, pp. 30-38, 1985

9. P. Ilser, W. Form, 'The Mechanism of Fire-Cracking', Journal of the Institute of Metals, Vol. 100, pp. 107-113, 1972 
10. P. Gainsbury, 'An Investigation into Fire-Cracking of an 18 Carat White Gold Alloy', The Worshipful Company of Goldsmiths, T.A.C., Project $6 a, 1970$

11. 'Guidelines for Manufacturing Jewellery and Associated Products in order to Avoid Nickel Allergy', CEN Technical Committee, CEN 283 WG4, Feb. 26, 1992

12. L. Gal-Or, 'Tarnish and Corrosion of Silver \& Gold Alloys', Santa Fe Symposium 1990, MetChem Research 1992, pp. 19-37

13. E.M. Wise, 'Gold: Recovery, Properties and Applications', D. Van Nostrand, Princeton, pp. 66 -93, 97-153, 1964

14. W. Rapson, 'Gold Usage', Academic Press, London, pp. 41-87, 1978

15. D. Ott, 'Metallurgical and Chemical Considerations in Jewellery Casting', Santa Fe Symposium 1988, Met-Chem Research Inc., pp. 223-244, 1989

16. D. Ott, C.J. Raub, 'Gold Casting Alloys', Gold Bull., 16(2), pp. 46-51, 1983

17. G. Raynor, 'The Alloying Behavior of Gold', Gold Bull., 9(1), pp. 12-19, 1976

18. K. Sager, J. Rodies, 'The Colour of Gold and its Alloys' Gold Bull., 10(1), pp. 10-14, 1977

19. C. Smithells, 'Metals Reference Book 5th Ed.', Butterworths, 1976
20. J. Atkinson, 'The Bleaching of Gold to Produce White Gold', The Worshipful Company of Goldsmiths, T.A.C Project No. 6a/2, 1972

21. L. Gal-Or, 'Gold Alloys', Santa Fe Symposium 1987, Met-Chem Research, pp. 57-74, 1988

22. L.S. Bonner et al., 'Precious Metals Science and Technology', IPMI, pp. 440-446, 1991

23. C. Susz, '18 Carat White Gold Alloys', Aurum (4), pp. 11-22, 1980

24. B. Taylor, 'The Work Hardening of 18 Carat White Gold', The Worshipful Company of Goldsmiths, T.A.C, Project No. 31, 1978

25. G. Normandeau, Imperial Smelting and Refining Technical Development Bulletin 8609S-1', Nov. 17, 1986

26. N. Taylor, United States Patent 1987451, January 8,1935

27. T. Koch, United States Patent 1340451, May 18, 1920

28. E.M. Wise, United States Patent 1577995, March 23, 1926

29. E.M. Wise, United States Patent 2050077, August 4, 1936

30. G. Sistare, E. Chamer, United States Patent 3512961, May 19, 1970

31. Metals Handbook, 9th Edition, Volume 2, American Society for Metals, pp. 680-683 